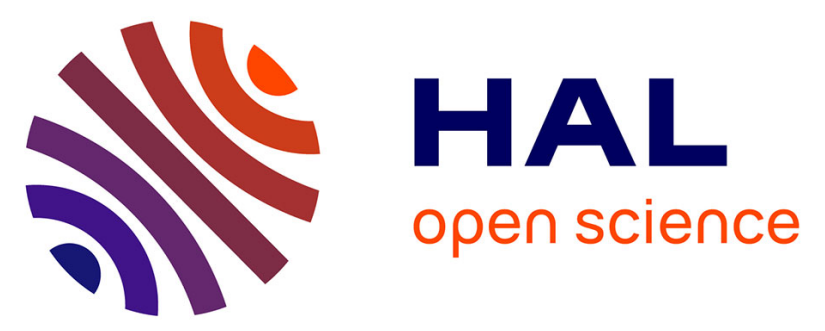

\title{
Ultrafine Fe-Fe2Ti eutectics by directed energy deposition: Insights into microstructure formation based on experimental techniques and phase field modelling
}

G. Requena, K. Bugelnig, F. Sket, S. Milenkovic, G. Rödler, A. Weisheit, J. Gussone, J. Haubrich, P. Barriobero-Vila, T. Pusztai, et al.

\section{To cite this version:}

G. Requena, K. Bugelnig, F. Sket, S. Milenkovic, G. Rödler, et al.. Ultrafine Fe-Fe2Ti eutectics by directed energy deposition: Insights into microstructure formation based on experimental techniques and phase field modelling. Additive Manufacturing, 2020, 33, pp.101133. 10.1016/j.addma.2020.101133 . hal-02568011

\section{HAL Id: hal-02568011 \\ https://hal.science/hal-02568011}

Submitted on 19 May 2020

HAL is a multi-disciplinary open access archive for the deposit and dissemination of scientific research documents, whether they are published or not. The documents may come from teaching and research institutions in France or abroad, or from public or private research centers.
L'archive ouverte pluridisciplinaire HAL, est destinée au dépôt et à la diffusion de documents scientifiques de niveau recherche, publiés ou non, émanant des établissements d'enseignement et de recherche français ou étrangers, des laboratoires publics ou privés. 


\title{
Ultrafine $\mathrm{Fe}-\mathrm{Fe}_{2} \mathrm{Ti}$ eutectics by directed energy deposition: Insights into microstructure formation based on experimental techniques and phase field modelling
}

\author{
G. Requena ${ }^{\mathrm{a}, \mathrm{g}}$, K. Bugelnig ${ }^{\mathrm{a}}$, F. Sket ${ }^{\mathrm{b}}$, S. Milenkovic ${ }^{\mathrm{b}}$, G. Rödler ${ }^{\mathrm{c}}$, A. Weisheit ${ }^{\mathrm{c}}$, J. Gussone ${ }^{\mathrm{a}}$, \\ J. Haubrich ${ }^{\mathrm{a}}$, P. Barriobero-Vila ${ }^{\mathrm{a}}$, T. Pusztai ${ }^{\mathrm{d}}$, L. Gránásy ${ }^{\mathrm{d}}$, A. Theofilatos ${ }^{\mathrm{e}}$, J.C. da Silva ${ }^{\mathrm{f}}$, \\ U. Hecht ${ }^{\mathrm{e}, *}$ \\ ${ }^{\text {a }}$ German Aerospace Center DLR, Institute of Materials Research, Linder Höhe, D-51147 Cologne, Germany \\ ${ }^{\mathrm{b}}$ IMDEA Materiales, Eric Kandel 2, Tecnogetafe, Getafe, 28906, Madrid, Spain \\ ${ }^{\mathrm{c}}$ Fraunhofer Institute for Laser Technology ILT, Steinbachstraße 15, 52074, Aachen, Germany \\ ${ }^{\mathrm{d}}$ Wigner Research Centre for Physics, Institute for Solid State Physics and Optics, Konkoly-Thege M. út 29-33, 1121, Budapest, Hungary \\ e Access e.V., Intzestr. 5, 52072, Aachen, Germany \\ ${ }^{\mathrm{f}}$ European Synchrotron Radiation Facility, Grenoble, France \\ ${ }^{\mathrm{g}}$ Metallic Structures and Materials Systems for Aerospace Engineering, RWTH Aachen University, 52062 Aachen, Germany
}

\section{A R T I C L E I N F O}

\section{Keywords:}

Directed energy deposition

Ultrafine eutectics

Computed tomography

Phase-field simulations

\begin{abstract}
A B S T R A C T
We investigated the $\mathrm{Fe}_{-} \mathrm{Fe}_{2} \mathrm{Ti}$ eutectic microstructure obtained by Directed Energy Deposition (DED) with a hypereutectic composition of Fe-17.6 at.\% Ti. Ultrafine lamellar spacings as low as $200 \mathrm{~nm}$ were achieved, features which otherwise can only be obtained in thin specimens, e.g. by suction casting. However, at interlayer boundaries (ILBs) a globular morphology of the primary $\mathrm{Fe}_{2} \mathrm{Ti}$ phase is observed with halos of the Fe phase. For the given DED conditions the crystalline structure is thus discontinuous across the ILBs. Both 2D and 3D analysis methods were used to quantify the microstructure, including high resolution synchrotron holographic X-ray computed tomography (HXCT). The generic behaviour of eutectic systems under conditions that qualitatively correspond to those of laser additive manufacturing was explored by phase-field modelling for selected nucleation scenarios and alloy compositions spanning from eutectic to hyper-eutectic. While providing valuable insights into microstructure formation, the simulations point out the need to further deepen our understanding about melting under additive manufacturing conditions in order to implement suitable nucleation and / or free growth models. The simulations also show that globular ILBs can be prevented when using exactly eutectic alloy compositions.
\end{abstract}

\section{Introduction}

Eutectic alloys have been in the focus of materials science and engineering over many decades because they are a prime example for spontaneous pattern formation and self-organization during solidification [1] while also bearing promise as in-situ composites with unique functional and structural properties. Their microstructure commonly consists of grains with a lamellar, fibrous, or more complex periodic arrangement of the solid phases. The characteristic length scales of the structure are the grain size (GS) and the eutectic spacing ( $\lambda$ ), both of which depend on the alloy composition and the processing conditions. A scaling law was proposed by Jackson and Hunt in 1966 [2] to link the average spacing $\bar{\lambda}$ to the local growth velocity $v$, e.g. $\bar{\lambda} \approx K \cdot v^{-0.5}$. The constant $\mathrm{K}$ depends solely on material properties.

The Jackson-Hunt ( $\mathrm{JH}$ ) scaling law holds for a large range of growth velocities, spanning over several orders of magnitude from about $10^{-7}$ to $10^{\circ} \mathrm{m} / \mathrm{s}$. Correction terms are necessary if growth occurs at very low velocity in a high temperature gradient. For high growth velocities the diffusion length $l_{d}=2 D / v$ may be as small as the spacing and under these conditions of rapid solidification the JH-scaling law must be amended [3] or even abandoned in favour of models that predict banded structure formation [4].

The growth velocities to be expected in Directed Energy Deposition (DED) commonly reach values in the order of $\sim 10^{-4} \mathrm{~m} / \mathrm{s}$ corresponding to the velocity of isotherms inside the melt pool underneath the travelling laser beam. For these conditions ultrafine eutectic

\footnotetext{
* Corresponding author.

E-mail address: u.hecht@access-technology.de (U. Hecht).
} 
spacings may be obtained, well below $500 \mathrm{~nm}$. This possibility seems to be unique: conventional casting cannot achieve the high cooling rates required to drive isotherms at such high velocity except potentially in small diameter capillaries. This has indeed been explored in so called suction casting experiments using arc melting followed by suction casting into cold metallic moulds with cylindrical cavities of diameter $\varnothing 1$ to $\varnothing 4 \mathrm{~mm}$. An impressive body of literature is published on ultrafine eutectics prepared by suction casting [[5] [6],], however without means to bridge towards applications. Laser additive manufacturing (L-AM) is the first technology to offer exploitation means for all the knowledge developed so far by the suction casting experiments, provided that structural inhomogeneities at interlayer boundaries can be avoided or tolerated. Here we present the results from ongoing research work dedicated to this subject. We selected the $\mathrm{Fe}^{-} \mathrm{Fe}_{2} \mathrm{Ti}$ eutectic for experiments and a generic A-B eutectic for modelling the structure evolution during DED. The ferrite-Laves phase eutectic $\mathrm{Fe}^{-} \mathrm{Fe}_{2} \mathrm{Ti}$ has been cast and described [[7]] as a potential material for high temperature applications and we attempted to investigate its manufacturing, microstructure and properties using DED.

This paper focusses on microstructure formation, characterization and modelling as follows: Section 2 describes sample manufacturing and the characteristic features observed in the microstructure, as well as a detailed analysis of the 3D microstructure obtained by high resolution synchrotron holographic X-ray computed tomography. Section 3 presents and discusses the results from phase field modelling and simulations which were set up to include AM-specific thermal boundary conditions for melting/remelting and solidification. Conclusions and an outlook to future work are given in Section 4.

\section{Experimental methods and microstructure characterization}

\subsection{Sample manufacturing and characteristic microstructure features}

The alloy Fe-17.6 at.\% Ti with a slightly hypereutectic composition (eutectic composition $\mathrm{c}_{\mathrm{E}}=15.8$ at.\% Ti) was selected for the experimental work. For a very similar alloy composition, e.g. Fe-18.1 at.\%Ti corresponding to $16 \mathrm{wt} . \% \mathrm{Ti}$, Tokoro et al. [8] reported the dependency of the average eutectic spacing $\bar{\lambda}$ on growth velocity based on unidirectional solidification experiments in a Bridgman furnace. From these data the Jackson-Hunt constant $\mathrm{K}$ was evaluated to be $\mathrm{K}=271$ $\mu \mathrm{m}^{3}$ /s. Other alloy properties were calculated with the Thermo-Calc software [9] and the database TCBIN, specifically the liquidus temperature $\mathrm{T}_{\text {liq }}$, the eutectic temperature $\mathrm{T}_{\mathrm{E}}$, the solidification interval $\Delta \mathrm{T}=\mathrm{T}_{\mathrm{liq}}-\mathrm{T}_{\mathrm{E}}$ and the phase fractions at $\mathrm{T}=\mathrm{T}_{\mathrm{E}}-\Delta \mathrm{T}$. Table 1 lists these alloy properties.

DED was conducted using a fiber coupled diode laser system with a maximum laser output of $2 \mathrm{~kW}$. The first samples with the dimensions of $4 \times 10 \times 3 \mathrm{~mm}^{3}$ were produced from Fe (99.8\%) and Ti $(99.7 \%)$ elemental powders blended in a tumble mixer. The particle size distribution of the elemental Fe-powder was $20-90 \mu \mathrm{m}$ and $45-90 \mu \mathrm{m}$ for the Ti-powder, respectively. The powder blend was fed through a coaxial nozzle by an inert gas stream of Ar, which also shields the melt pool from the surrounding atmosphere. DED was carried out with a bidirectional hatching strategy using a 1.4301 steel substrate at room temperature and the parameters listed in Table 2. The main microstructure characteristics are displayed in Fig. 1, from optical microscopy (Fig.1a) and backscatter electron microscopy (Fig. 1.b).

The two-phase eutectic microstructure is composed of the hexagonal
Table 2

DED process parameters for a small sample with dimensions of $4 \times 10 \times 3$ $\mathrm{mm}^{3}$.

\begin{tabular}{lllll}
\hline $\begin{array}{l}\text { Laser } \\
\text { Power }(\mathrm{W})\end{array}$ & $\begin{array}{l}\text { Velocity } \\
(\mathrm{mm} / \mathrm{min})\end{array}$ & $\begin{array}{l}\text { Powder Mass } \\
\text { Flow }(\mathrm{g} / \mathrm{min})\end{array}$ & $\begin{array}{l}\text { Laser Beam } \\
\text { Diameter }(\mathrm{mm})\end{array}$ & $\begin{array}{l}\text { Layer Height } \\
(\mathrm{mm})\end{array}$ \\
\hline 200 & 800 & 1.2 & 0.6 & 0.2 \\
\hline
\end{tabular}

Laves phase $\mathrm{Fe}_{2} \mathrm{Ti}$ (space group no. 194) and the body centered $\alpha(\mathrm{Fe})$ (space group no. 229) with elongated lamellar grains inside the bulk volume of the layers / tracks. At interlayer boundaries however, the microstructure is globular, being composed of rounded primary $\mathrm{Fe}_{2} \mathrm{Ti}$ particles which are enveloped by $\alpha(\mathrm{Fe})$ halos. The thickness of the interlayer boundaries (ILBs) ranges around $\delta=12 \pm 5 \mu \mathrm{m}$, while the eutectic spacing in the lamellar grains ranges around $\lambda=190 \pm 25 \mathrm{~nm}$ (compare Fig. 5 in section 2.2.). More details are revealed by electron backscatter diffraction (EBSD) as shown in Fig. 2. The EBSD maps were acquired in an SEM type Zeiss Gemini 1550 equipped with a HKL Nordlys detector and using the software Oxford INCA Crystal. The maps in Figs. 2(a) for $\mathrm{Fe}_{2} \mathrm{Ti}$ and $\alpha(\mathrm{Fe})$ respectively, encompass one ILB running from the upper left to the lower right side of the map. The crystal orientations are provided as inverse pole figure colour maps relative to one direction only (here the transverse direction TD was chosen). It is noteworthy to observe that for the given DED process parameters the crystalline orientation of both phases is discontinuous across the ILB. A magnified view of the crystal structure inside the ILB is presented in Figs. 2(b), showing the globular $\mathrm{Fe}_{2} \mathrm{Ti}$ phase particles being enveloped by halos of $\alpha(\mathrm{Fe})$. In each $\alpha(\mathrm{Fe})$ halo several $\alpha(\mathrm{Fe})$ grains can be identified. From the top-most globular particles new grains develop into the following layer.

The origin of the globular morphology at interlayer boundaries is proposed to follow the sequence of events (i) through (iii) upon melting of the previously deposited layer as follows: (i) Initially the alloy displays coupled eutectic growth, even if the composition is hyper-eutectic on the primary $\mathrm{Fe}_{2}$ Ti-side of the phase diagram. Therefore, the bulk structure is a lamellar eutectic. (ii) Upon melting, some part of the previously deposited layer will melt completely. However, at the bottom of the melt pool the system will evolve towards thermodynamic equilibrium and display a mushy zone composed of primary $\mathrm{Fe}_{2} \mathrm{Ti}+$ Liquid over a distance $\delta$ that roughly corresponds to the ratio between the solidification interval $\Delta \mathbf{T}=\mathbf{T}_{\mathbf{l i q}}-\mathbf{T}_{\mathrm{e}}$. and the temperature gradient $\boldsymbol{G}$. In this region, primary $\mathrm{Fe}_{2} \mathrm{Ti}$ lamellae remain unmolten protruding into the surrounding liquid like thin plates. The thin plates in contact with the liquid will undergo a fragmentation process. It is not fully clear, whether this process is a Plateau-Rayleigh capillary instability accomplished through an interface perturbation [10,11] or simply a fast melting and rupture process at random locations, e.g. at subgrain boundaries, dislocations etc. Recent literature based on MD simulations [12,13] indeed reports on pathways to very fast melting. Wu et al. [13] report rupture times of about $12 \mathrm{~ms}$ for a $10 \mu \mathrm{m}$ diameter rod. To our best knowledge, similar results for plates have not been reported. Investigating the details of the fragmentation process remains a challenging research task for the future. (iii) The fragmentation process is necessarily accompanied by partial dissolution of $\mathrm{Fe}_{2} \mathrm{Ti}$ fragments, more pronounced in the upper part of the mushy zone. This is because the phase fraction of $\mathrm{Fe}_{2} \mathrm{Ti}$ in the mushy zone depends on the local temperature in the temperature gradient. The fragments are free to spheroidize, move and rotate along with the flow in the melt pool. At

Table 1

Alloy Fe-17.6 at.\% Ti thermodynamic equilibrium data.

\begin{tabular}{|c|c|c|c|c|}
\hline Alloy, at.\% & $\mathrm{T}_{\text {liq }},{ }^{\circ} \mathrm{C}$ & Eutectic temperature, ${ }^{\circ} \mathrm{C}$ & Solidification interval, ${ }^{\circ} \mathrm{C}$ & $\begin{array}{l}\text { Phase fractions } \\
@ \mathrm{~T}=\mathrm{T}_{\mathrm{E}}-\Delta \mathrm{T}, \mathrm{mol} \%\end{array}$ \\
\hline Fe-17.6 Ti & 1323 & 1292 & 31 & $44.1 \mathrm{~mol} \% \mathrm{Fe}_{2} \mathrm{Ti}$ \\
\hline
\end{tabular}




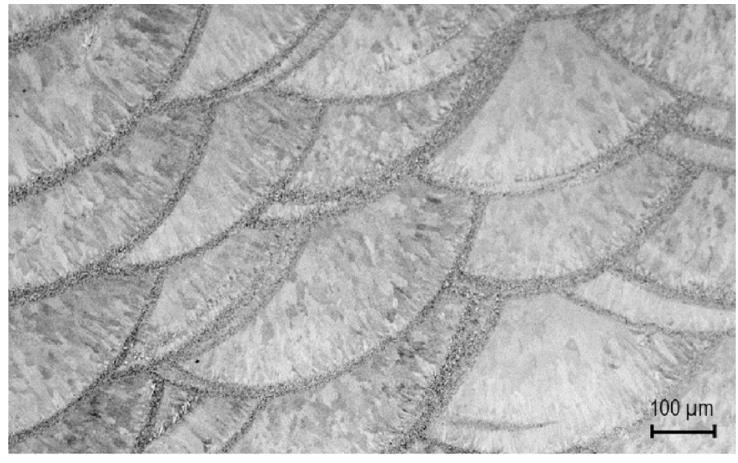

(a)

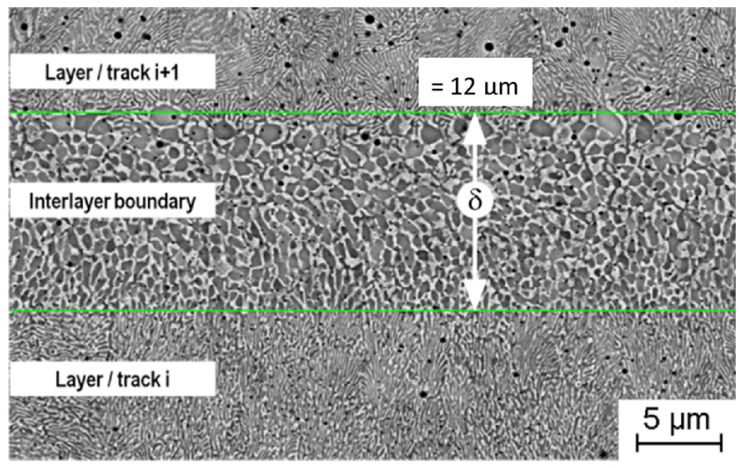

(b)

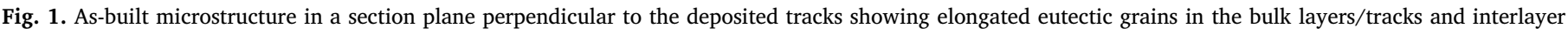
boundaries of thickness " $\delta$ " with a distinct, globular morphology; (a) optical microscopy, (b) backscatter electron microscopy.
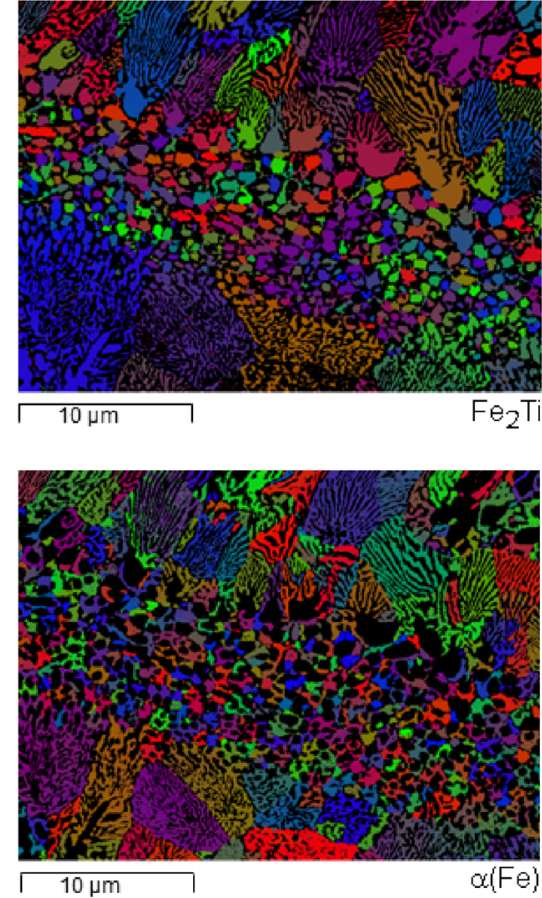

(a) Transverse direction TD $\rightarrow$

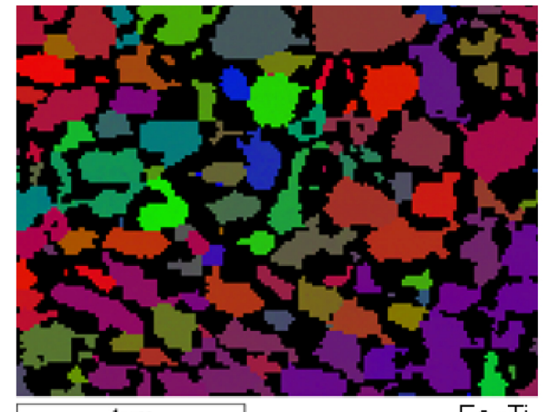

$4 \mu \mathrm{m}$

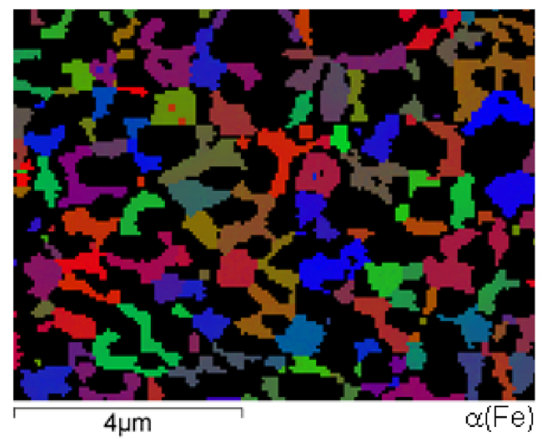

(b) Transverse direction TD $\rightarrow$
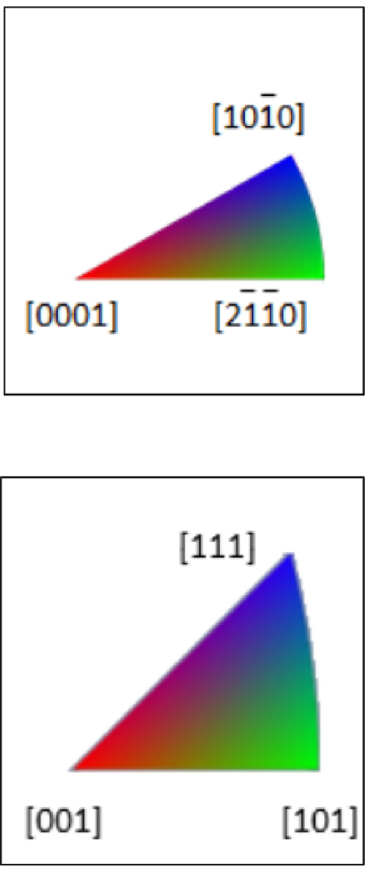

(c) IPF triangle

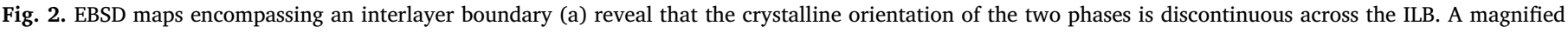

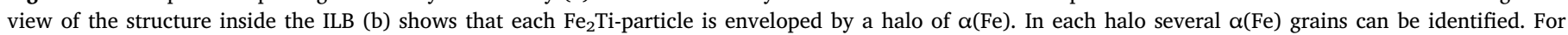

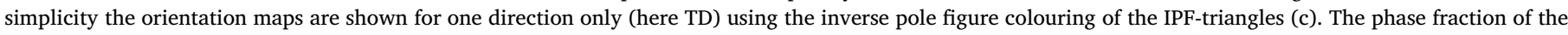
Fe-phase is calculated to be $49.4 \%$ and for the $\mathrm{Fe}_{2} \mathrm{Ti}$ phase $50.5 \%$.

the transition from melting to solidification these fragments will experience free growth and the top-most ones will further re-initiate coupled growth.

For laser-based AM-conditions, however, more research work is required in order to fully understand the process of melting, fragmentation and the interlayer boundary solidification structures as well as their impact on mechanical properties. Irrespective of the open questions, the microstructure analysis results may be summarized along the following lines:

(i) From the thickness of the interlayer boundaries $\delta=12 \pm 5 \mu \mathrm{m}$ one may estimate the local temperature gradient $G$ at the bottom of the melt pool $\boldsymbol{G}=\boldsymbol{\Delta} \boldsymbol{T} / \delta$. Here $\Delta \mathrm{T}$ is the solidification interval of the slightly hypereutectic alloy, as listed in Table 1 . For this sample the estimated value is $\boldsymbol{G} \sim 2.6 \times 10^{6} \mathbf{K} / \mathbf{m}$. As highlighted before, more research including melt pool simulations are required to refine this analysis. (ii) From the average lamellar spacing $\lambda=190 \pm 25 \mathrm{~nm}$ in the bulk eutectic grains one may estimate the local growth velocity $\boldsymbol{v}$ corresponding to the average isotherm velocity in the melt pool using the Jackson-Hunt scaling law $\boldsymbol{v}=\boldsymbol{K}_{\boldsymbol{J H}} / \boldsymbol{\lambda}^{2}$. For this sample the estimated value is $\boldsymbol{v} \sim 7.5 \times 10^{-3} \mathrm{~m} / \mathrm{s}$. The order of magnitude seems to be in reasonable agreement with the applied laser scanning velocity $V_{L}$ of $800 \mathrm{~mm} / \mathrm{min}$ which amounts to $V_{\boldsymbol{L}}=13 \times 10^{-3} \mathbf{m} / \mathbf{s}$. Since the melt pool is solidified from virtually two sides (radially), the necessary growth velocity expected in a steady state process would correspond to roughly half the laser scanning velocity. Melt pool simualtions are currently ongoing to refine this analysis. For comparison, the lamellar spacing obtained in the same alloy by suction casting in a rod with a $3 \times 3 \mathrm{~mm}$ cross sectional area amounts to $\lambda=720 \pm 180 \mathrm{~nm}$, as will be presented elsewhere. 
Table 3

Parameters for HXCT experiments at the beamline ID16A/ESRF.

\begin{tabular}{|c|c|c|c|c|c|c|}
\hline Detector & $\begin{array}{l}\text { Energy } \\
(\mathrm{keV})\end{array}$ & $\begin{array}{l}\text { Field of view } \\
\left(\mu \mathrm{m}^{2}\right)\end{array}$ & $\begin{array}{l}\text { Sample-to- } \\
\text { detector distance } \\
(\mathrm{mm})\end{array}$ & $\begin{array}{l}\text { Exposure time } \\
\text { (s/proj) }\end{array}$ & Proj. & $\begin{array}{l}\text { Voxel size } \\
\left(\mathrm{nm}^{3}\right)\end{array}$ \\
\hline CCD & 33.6 & $20.5 \times 20.5$ & $\begin{array}{l}4.19 \\
4.37 \\
5.09 \\
6.59\end{array}$ & 0.25 & 2000/distance & $10^{3}$ \\
\hline
\end{tabular}

\subsection{Microstructure characterization by high resolution synchrotron holographic X-ray computed tomography (HXCT)}

The 3D microstructure of the Fe-17.6 at.\%Ti DED sample was investigated using synchrotron holographic X-ray computed tomography (HXCT) at the nano-imaging beamline ID16A of the European Synchrotron Research Facility (ESRF), Grenoble, France [14]. To this purpose, a cylindrical sample with a diameter of $\sim 15 \mu \mathrm{m}$ and $\sim 20 \mu \mathrm{m}$ height was prepared by focused ion beam (FIB) in a FEI Helios Nanolab 600 i dual beam microscope from a representative region containing the interface between the globular and the lamellar region (see Fig. 1b). In fact, the volume was extracted from the bottom part of an ILB encompassing a lamellar region just below the ILB (at the bottom of a melt pool).

Table 3 displays the parameters used for HXCT. The sample was illuminated with a magnifying X-ray cone beam of $33.6 \mathrm{keV}$ focused by Kirkpatrick-Baez mirrors using the zoom HXCT approach [15]. 2000 projections were acquired between $0^{\circ}-180^{\circ}$ with acquisition times of $\sim$ $1 \mathrm{~s} /$ projection employing a CCD camera at four sample-to-focal-point distances $(4.19,4.37,5.09$ and $6.59 \mathrm{~mm}$ ) for efficient phase retrieval of the holo-tomographic reconstruction. The experiment was carried out under ultra-high vacuum atmosphere.

The following steps were performed to analyse the 3D data:

(i) Reconstruction of the tomographic volume was performed by using a filtered back projection algorithm implemented in the PySHT software of the ESRF with a resulting voxel size of $\left(10 \mathrm{~nm}^{3}\right)$. Prior to segmentation, the quality of the reconstructed volume was improved using a band pass filter and 2D or 3D anisotropic diffusion filters available in Fiji [16] and Avizo Fire 9.5 in order to minimize ring artefacts and smooth the images. After filtering, the volume was converted from 16 to 8 bit format and the grey value histogram was inverted so that the appearance of the microstructural constituents is analogous to SEM-BSE images.

(ii) The segmentation of the microstructural constituents was carried out by global grey value thresholding applying three different grey value thresholds for each segmented constituent (best threshold determined by eye \pm 2 grey values) to ensure better representativity. 3D visualizations were produced using Avizo Fire 9.5.

(iii) The quantification of the 3D microstructure of the material was carried out for the entire volume of $\sim 12.1 \times 10.8 \times 12.6 \mu \mathrm{m}^{3}$ as well as for individual volumes containing separately the eutectic lamellar region $\left(7.4 \times 10.8 \times 12.6 \mu \mathrm{m}^{3}\right)$ and the globular interlayer boundary $\left(4.7 \times 10.8 \times 12.6 \mu \mathrm{m}^{3}\right)$. The global interconnectivity of the $\mathrm{Fe}$ and $\mathrm{Fe}_{2} \mathrm{Ti}$ phases was calculated as the volume of the largest particle divided by the total volume of the phase considered [17,18]. The 3D thickness distribution was determined individually for the $\mathrm{Fe}$ and $\mathrm{Fe}_{2} \mathrm{Ti}$ phases using the software Avizo Fire 9.5 to evaluate the coarseness of the microstructure. This parameter is calculated for each voxel of the considered phase after skeletonization and is defined as the diameter of the largest sphere that fits within the considered structure [18].

Fig. 3 depicts the as-reconstructed HXCT volume and a portion of a reconstructed HXCT slice. This volume / slice contains few coarse $\alpha(\mathrm{Fe})$ particles just below the interlayer boundary. These particles are not predominant for the whole sample volume (compare Fig. 1 and Fig. 2). The volume also contains a small amount of oxide particles and fine pores (black). We were not able to make a clear distinction between oxides and pores.

Fig. 4 shows 3D visualizations of the as-reconstructed volume of $12.1 \times 10.8 \times 12.6 \mu \mathrm{m}^{3}$ with the $\mathrm{Fe}$ (a) and $\mathrm{Fe}_{2} \mathrm{Ti}(\mathrm{b})$ phases segmented separately. The blue dashed line indicates the boundary between the lamellar and globular regions. The $\mathrm{Fe}$ (blue) and $\mathrm{Fe}_{2} \mathrm{Ti}$ - (red) phases form highly interconnected 3D networks which are coarser in the globular region. The volumes are also shown in color-coded views corresponding to the 3D thickness of the phases (c), (d). The coarse spherical $\alpha(\mathrm{Fe})$ particles emerge with orange colour (c-d) being heterogeneously distributed in the lamellar region just below the globular ILB region. Inclusions, likely oxide particles, not shown here, were found in the center of the Fe spheres, but never in the centers of the globular $\mathrm{Fe}_{2} \mathrm{Ti}$ particles. The $\alpha(\mathrm{Fe})$ and $\mathrm{Fe}_{2} \mathrm{Ti}$ phases both present a global interconnectivity $\sim 99 \%$ and volume fractions of $46.44 \pm 2.2$ vol. $\%$ and $39.95 \pm 2$ vol. $\%$ for the Fe-network and $47.02 \pm 2.3$ vol. $\%$ and $66.58 \pm 2.6$ vol. $\%$ for the $\mathrm{Fe}_{2} \mathrm{Ti}$-network in the lamellar and globular regions, respectively. Spherical Fe has a volume fraction of $1.1 \pm 0.03 \mathrm{vol}$. \% within the entire volume, while oxides/pores have a sphericity between $0.6-1$, an aspect ratio between $1.2-2.5$ and represent a volume fraction of $0.34 \pm 0.02 \mathrm{vol}$. $\%$ within the entire volume.

Fig. 5 shows the evaluated 3D thickness distributions determined for the Fe-network (a) (b) and the $\mathrm{Fe}_{2} \mathrm{Ti}$ network (c), (d), respectively. The relative frequency distributions are displayed separately for the lamellar region (a), (c), and for the globular region inside the ILB (b), (d) being displayed in blue and red color, respectively. A clear difference in coarseness between the lamellar and globular regions can be seen. The thickness of the phases in the lamellar region peaks around $100 \mathrm{~nm}$, which corresponds to an average lamellar spacing $\lambda$ of about $200 \mathrm{~nm}$.

For the globular region, comparatively coarser structures with $3 \mathrm{D}$ thicknesses up to $\sim 0.36 \mu \mathrm{m}$ for the Fe-network and up to $\sim 0.5 \mu \mathrm{m}$ for the $\mathrm{Fe}_{2} \mathrm{Ti}$ can be observed. The few coarse Fe-particles have a diameter in the range from 0.28 to $1.04 \mu \mathrm{m}$.

\section{A phase field model for successive remelting and solidification under AM-conditions}

The experiments provide detailed information on the crystallographic orientation within the multigrain eutectic structure formed during DED, therefore, we used a specific phase-field model that is able to describe the orientational relationships in such systems [19]. In this model, the local state is characterized by three fields: a space- and time dependent phase field $\varphi(\mathbf{r}, t)$ that monitors the melting and freezing of the liquid (liquid: $\varphi=0$; solid: $\varphi=1$ ), a concentration field $c(\mathbf{r}, t)$, and an orientation field $\theta(\mathbf{r}, t)$. The latter represents the local crystallographic orientation (scalar field in two dimensions) [20-23], and is needed to facilitate comparison with the orientation maps from EBSD experiments. For the sake of brevity, we present here only the free energy functional and the equations of motion, for further details refer to [19]:

Free energy:

$F=\int d^{3} r\left\{\frac{\varepsilon_{\varphi}^{2} T}{2} s^{2}(\vartheta-\theta)|\nabla \varphi|^{2}+\frac{\varepsilon_{c}^{2} T}{2}|\nabla c|^{2}+f_{\text {bulk }}+f_{\text {ori }}\right\}$, 


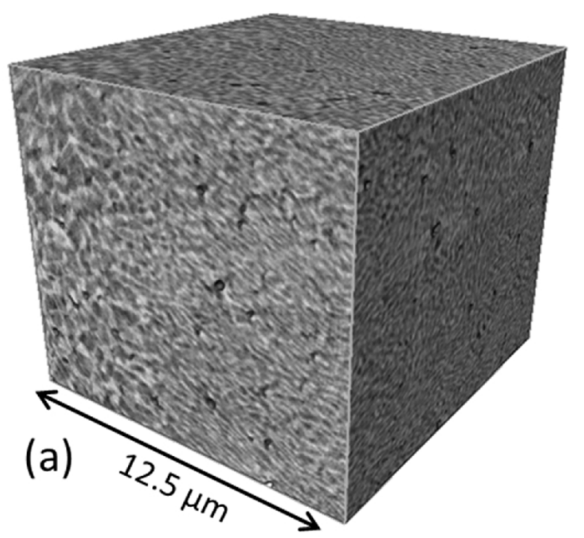

(a)

Fe - network
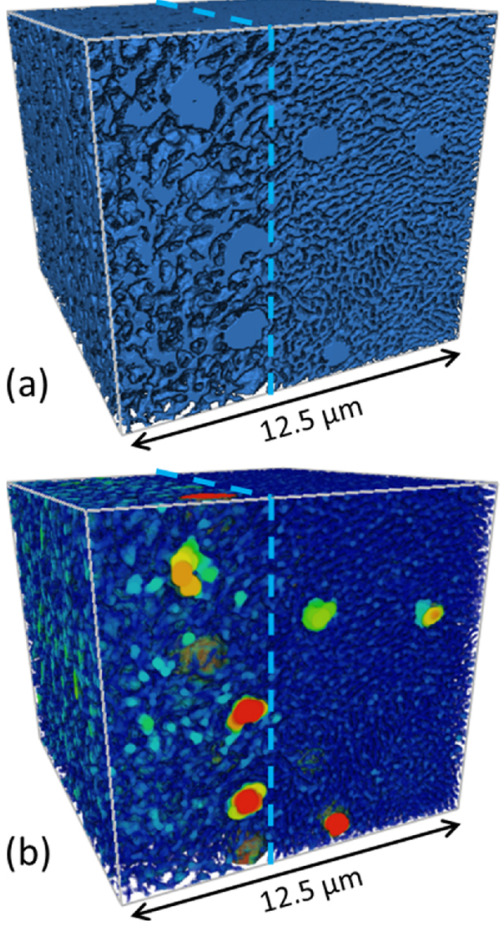

Build direction

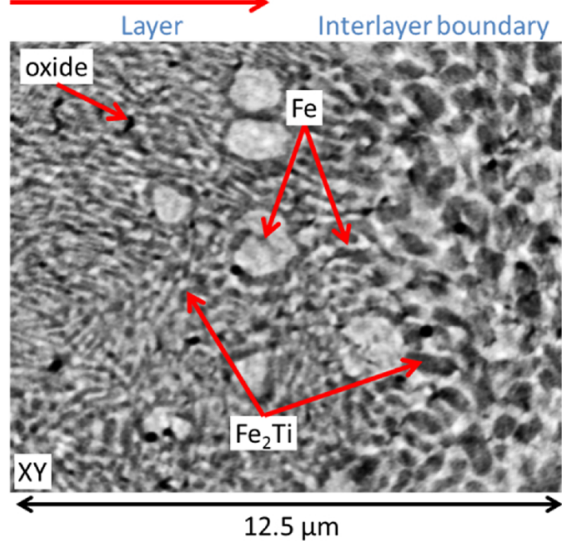

(b)

$12.5 \mu \mathrm{m}$
$\mathrm{Fe}_{2} \mathrm{Ti}$ - network
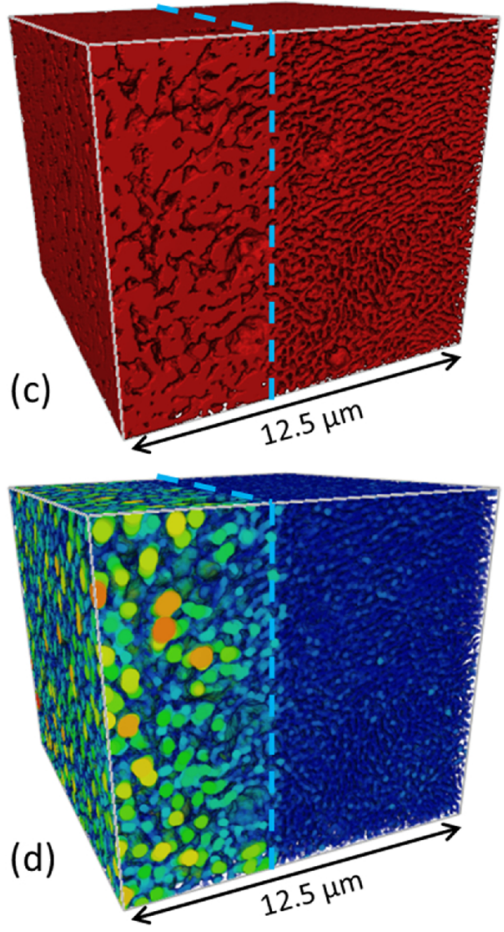

Fig. 3. 3D visualization of (a) the as-reconstructed HXCT volume (a) and portion of a reconstructed HXCT slice (b) at the interface region containing lamellar and globular structures; bright grey $=\mathrm{Fe}$, dark grey $=\mathrm{Fe}_{2} \mathrm{Ti}$, black $=$ oxides. $\quad$ ROI: $\quad \sim 12.1 \times 10.8 \times$ $12.6 \mu \mathrm{m}^{3}$, voxel size $=10 \times 10 \times 10 \mathrm{~nm}^{3}$.
3D Thickness $[\mu \mathrm{m}]$

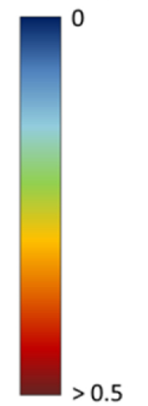

Fig. 4. 3D visualization of the (a) Fe-network and (b) $\mathrm{Fe}_{2}$ Ti-network and the corresponding 3D thickness distributions (c, d); the lamellar/ globular boundary is indicated by the dashed blue line; ROI: $\sim 12.1 \times 10.8 \times 12.6 \mu \mathrm{m}^{3}$, voxel size $=10 \times 10 \times 10 \mathrm{~nm}^{3}$. where $f_{\text {bulk }}=w(c) \operatorname{Tg}(\varphi)+[1-p(\varphi)] f_{\mathrm{L}}(c, T)+p(\varphi) f_{\mathrm{S}}(c, T)$, whereas $w$ $(c)=(1-c) w_{\mathrm{A}}+c w_{\mathrm{B}}$, the $g(\varphi)=1 / 4 \varphi^{2}(1-\varphi)^{2}$ and $p(\varphi)=\varphi^{3}(10-$ $\left.15 \varphi+6 \varphi^{2}\right)$ are the double well and interpolation functions. Here $f_{\text {ori }}=p(\varphi) H\left\{h(c) F_{1}(|\nabla \theta|)+[1-h(c)] F_{2}(|\nabla \theta|)+\left(\varepsilon_{\theta}^{2} H / 2 T\right)|\nabla \theta|^{2}\right\}$ is a specific free energy term, that keeps a fixed orientational relationship between the two solid phases [1], $h(c)=1 / 2\left\{1+\cos \left[2 \pi\left(c-c_{\alpha}\right) /\left(c_{\beta}-\right.\right.\right.$ $\left.\left.\left.c_{\alpha}\right)\right]\right\}, c_{\alpha}$ and $c_{\beta}$ are the concentrations in the two solid phases, whereas $F_{1}(|\nabla \theta|)=|\nabla \theta|$ and $F_{2}(|\nabla \theta|)=a+b|\cos (2 m \pi d|\nabla \theta|+\psi)|$, while $a, b$, $m$, are constants, and $d$ is the characteristic thickness of the $\alpha-\beta$ phase boundary. Variationally derived equations of motion were used for the three fields: $\partial \varphi / \partial t=-M_{\varphi}\{\delta F / \delta \varphi\}, \partial c / \partial t=\nabla\left[M_{c} \nabla\{\delta F / \delta c\}\right]$, and $\partial \theta / \partial t$ $=-M_{\theta}\{\delta F / \delta \theta\}$, where $M_{\varphi}, M_{c}$, and $M_{\theta}$ are the mobilities that determine the timescale of the evolution of the individual fields. For details and the choice of model parameters see [16]. This model works properly if we use the physical interface thickness, which is on the nm scale. This restricts us to much smaller length and time scales, and thus, to cooling/heating rates and temperature gradients that are much higher than in our experiments. Accordingly, here we explore the generic behaviour of eutectic systems under conditions that qualitatively, but not quantitatively correspond to those of laser additive manufacturing. Nonetheless the results obtained on the small size and time scales of the simulations can be scaled up to the experimental conditions relying on the Jackson-Hunt scaling law. Indeed, a recent study by Wang and Trivedi indicates that the Jackson-Hunt scaling remains valid down to a few nanometers in a metallic alloy [3].

We performed 2D simulations for a simple binary eutectic model system represented by a regular solution model for components A and B that yields the symmetric phase diagram shown in Fig. 6 (a). The equations of motion were solved numerically with simple finite differencing and forward Euler time-stepping. To keep the computations tractable, only the topmost part of the material was included in the simulation domain, which was the size of $1000 \times 2000$ pixels, corresponding to a 2D section perpendicular to the laser movement direction. We modelled the addition of new layers, the partial remelting of the matter by the laser beam, and the full solidification of the melt by the cyclic repetition of a shorter heating and a longer cooling period, as 


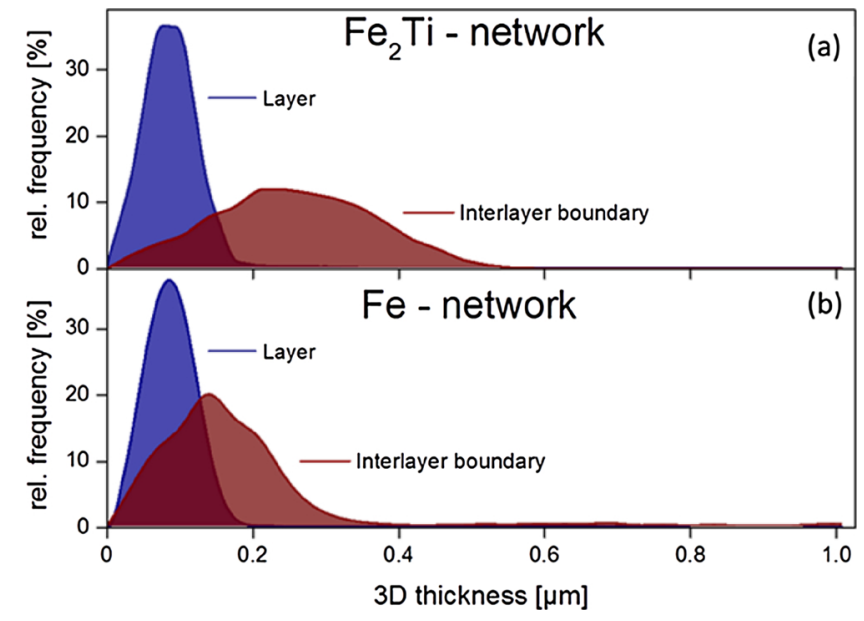

Fig. 5. Quantitative evaluation of $3 \mathrm{D}$ thickness distributions within the (a) $\mathrm{Fe}_{2}$ Ti-network and (b) Fe-network for the lamellar region (blue) and the interlayer boundary region (red).

detailed in Section 3.1. The temperature programme applied is shown in Fig. 6 (b).

We note that the sample size and the spatiotemporal behaviour of the temperature shown in Fig. 6 (b) provides an average temperature gradient of about $8 \times 10^{8} \mathrm{~K} / \mathrm{m}$ and heating/cooling rates of about $10^{10}$ $\mathrm{K} / \mathrm{s}$, approximating reasonably the conditions for melting by nanosecond laser pulses [24]. Qualitatively similar behaviour is expected in laser additive manufacturing, however, we note again that in the present computations the heating/cooling rates and the thermal gradient are much larger than in the experiments. This choice is a compromise that enables us to compute several heating/cooling cycles within our model.

Using our phase-field model, we explored two theoretical possibilities for the formation of the globular microstructure at the interlayer boundaries: (1) Homogeneous nucleation, (2) Heterogeneous nucleation via free growth on foreign seed particles or small primary phase fragments. Evidently, homogeneous nucleation is only a theoretical possibility [25], as usually volumetric heterogeneities initiate the process in metallic melts. These can be either foreign seed particles (e.g. oxides) or small fragment particles inherited from the previous melting step. Homogeneous nucleation according to mechanism (1) was achieved by adding noise to the equations of motion as done in the original model [19]; whereas mechanisms (2) were realized by adding randomly placed dormant particles, either foreign seed particles or primary phase fragments, following the athermal nucleation and free

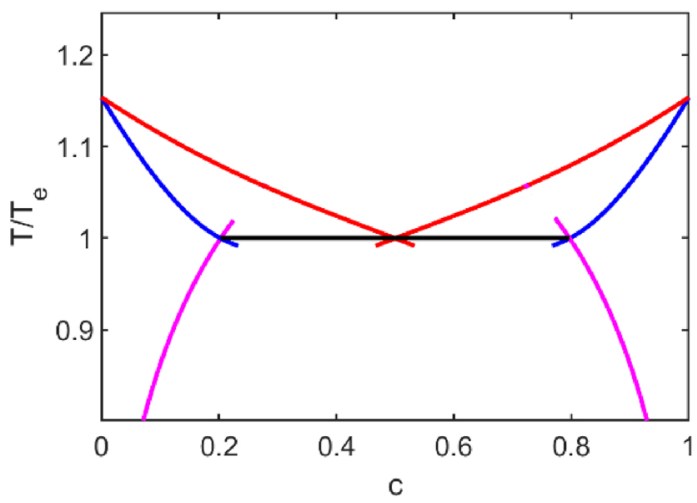

(a) growth model of Quested and Greer [26]. The dormant particles were randomly oriented crystallites, which are activated and experience free growth when a sufficiently high undercooling is reached. The critical undercooling depends on the size of the particle or fragment via capillary terms.

\subsection{Modelling results and discussion}

We performed phase-field simulations to investigate the origin of the generic microstructure seen in laser AM shown in the previous section for $\mathrm{Fe}_{-} \mathrm{Fe}_{2} \mathrm{Ti}$ and in the literature for the $\mathrm{Ni}-\mathrm{Ni}_{3} \mathrm{Sn}$ eutectic [27]. The modelling of the heating/cooling steps was as follows:

The heating period, which corresponds to the laser beam travelling over the simulation domain, was modelled by prescribing an elevated temperature profile. First, the top half of the simulation domain was shifted downwards to replace the bottom half of the simulation domain and a new liquid layer of a hyper-eutectic composition $c=0.6$ was added on top to fill the upper half of the simulation box (Fig. 7 (a)). This procedure models the addition of a layer of new material on the top (for simplicity, we did not model the melting of the powder), while moving out the lower part of the already solidified material at the bottom of the simulation box. The high temperature kept during the heating period resulted in the partial remelting of the topmost part of the lamellae solidified in the previous cycle, increasing the amount of the melt (Fig. 7 (b)).

The subsequent cooling period was modelled by switching to a lower temperature profile. As a result, melting is replaced by epitaxial growth of the lamellar structure but with simultaneous appearance of small globular particles of the primary phase ahead of the solidification front. This happens either by homogeneous nucleation driven by the fluctuations added to the phase-field equation of motion (Figs. 7 and 8), or by free growth on the virtual seeding particles added to the system (Fig. 9), as described above in the model description section. We made simulations with both mechanisms. In all cases, the new particles appear only in the liquid region of the highest undercooling, i.e., at the bottom part of the melt pool (Fig. 7 (c)). Then the nucleated particles start to grow. Most of them will coalesce shortly, forming a layer of globular particles that are rich in component B and are surrounded by a halo, rich in component $\mathrm{A}$. This globular layer blocks the growth of the remelted lamellae below. Those particles that are on the topmost part of the globular layer have the chance to grow further and develop into the lamellar eutectic grains that fill up the remaining space (Fig. 7 (d)).

Repeating these steps, a layered structure forms, as shown by the montage of images displayed in Fig. 8. This structure is qualitatively similar to the one observed in the experiments. The small globular grains resulting from nucleation constitute the interlayer boundaries (ILBs) between the lamellar layers. As nucleation is a random event,

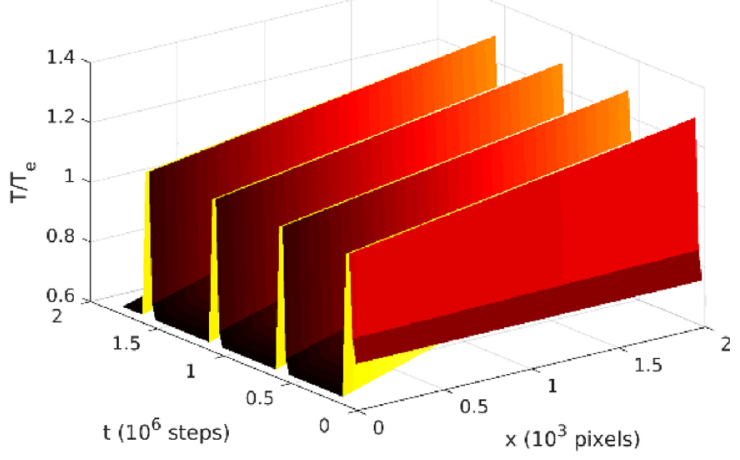

(b)

Fig. 6. (a) The symmetric eutectic phase diagram corresponding to the generic regular solution alloy used in our phase-field simulations and (b) the thermal history assumed for modelling the laser additive manufacturing. 


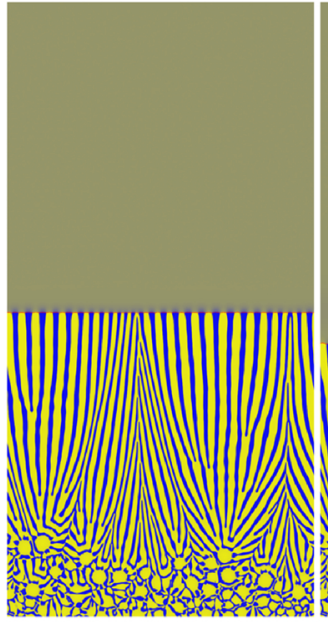

(a)

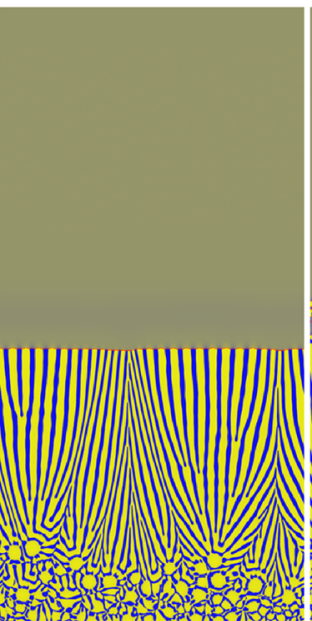

(b)

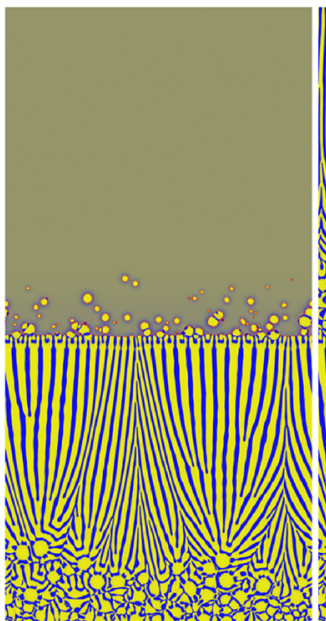

(c)

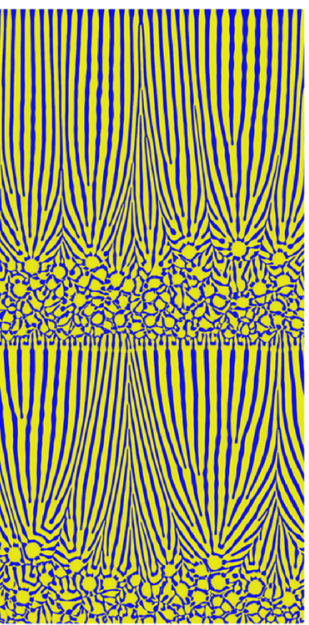

(d)

Heating / melting

Cooling / solidification

Fig. 7. Snapshots of the composition map from the phase-field simulation of melting and solidification during a full heating/cooling cycle of laser additive manufacturing. Time elapses from left to right showing (a) the lamellar eutectic structure from the previous cycle and freshly melted powder on the top, (b) the remelting of the topmost part of the lamellar structure during heating, (c) the epitaxial growth of the lamellae and the nucleation of the primary phase ahead and (d) the subsequent growth of elongated eutectic grains during cooling. At this point, the simulation domain is stepped up by half the sample height and a new heating/cooling cycle can be started with a configuration similar to (a). Note that $c_{0}=0.6$.
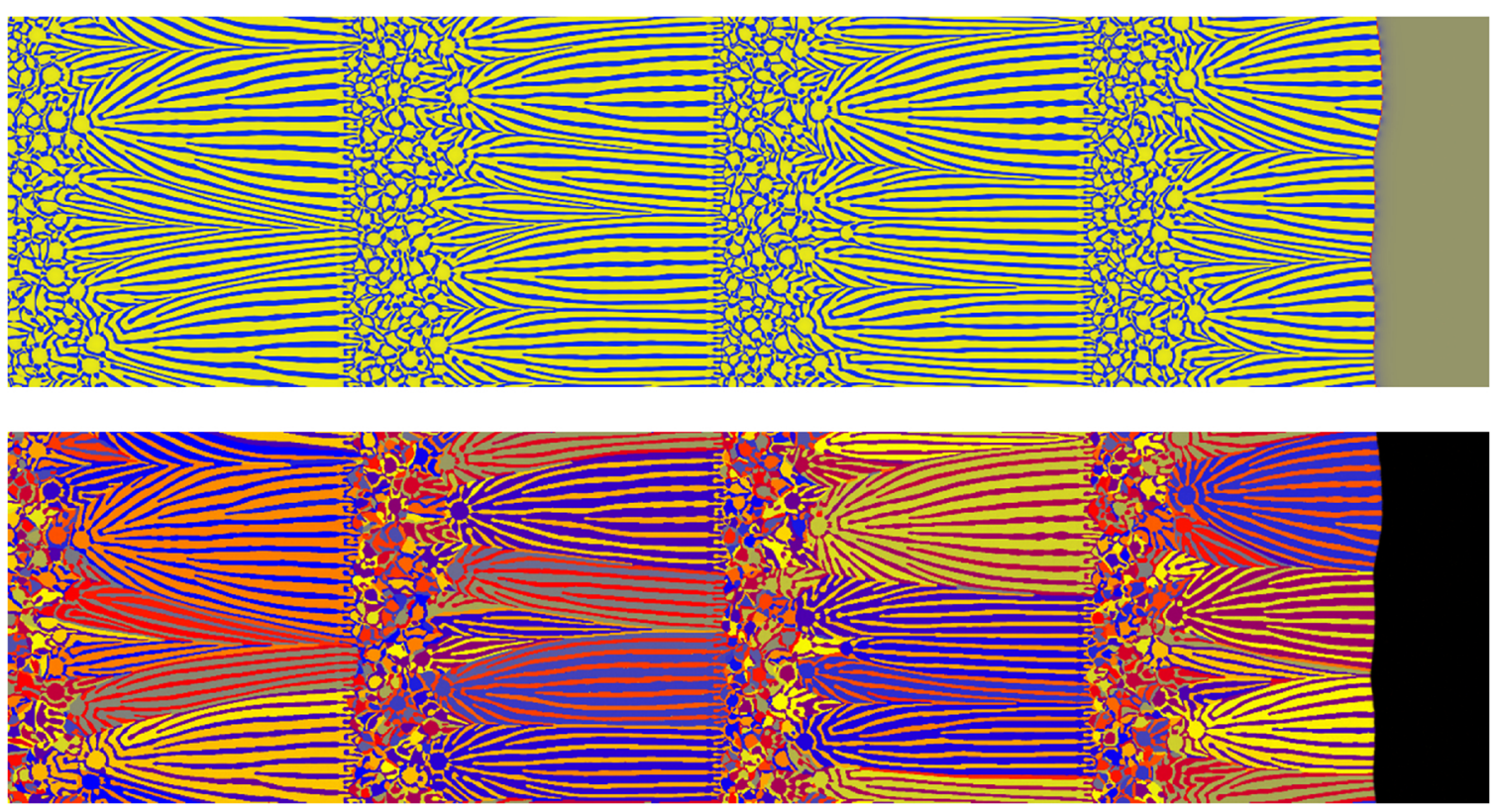

Fig. 8. Layered globular-lamellar structure as predicted by the phase-field simulation, the top row displays the concentration map, the bottom row the crystal orientation map. The images are composed of snapshots taken at different times. The montage was rotated 90 degrees clockwise, so the growth direction is from left to right. Note that $c_{0}=0.6$.
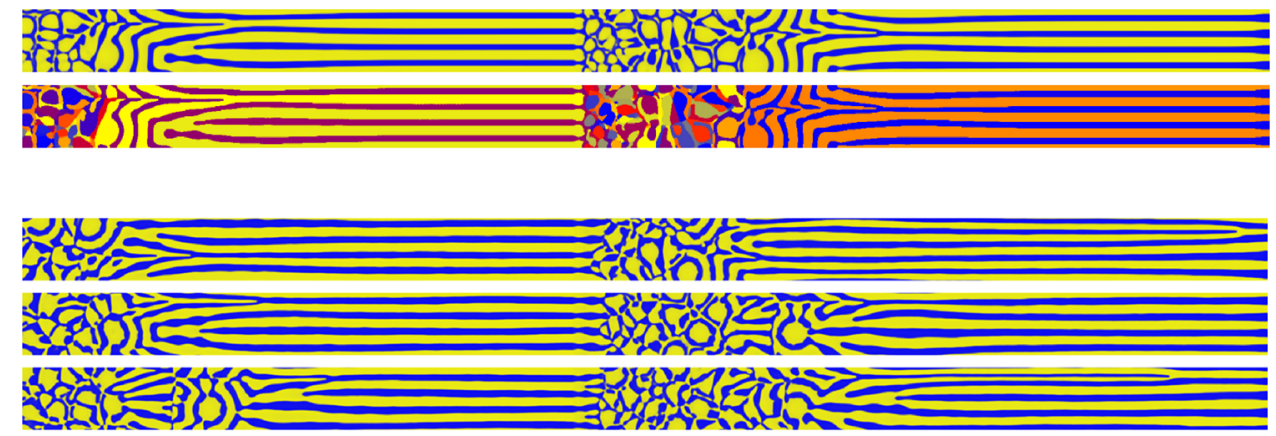

Fig. 9. Eutectic microstructure predicted assuming particle induced heterogeneous nucleation and free growth with $c_{0}=0.6$. Top: composition field, bottom: orientation field.

Fig. 10. The effect of temperature on the final microstructure as predicted by the phase-field simulations. The second and third panels display simulations, in which the temperature during the cooling stages were $10 \mathrm{~K}$ and $20 \mathrm{~K}$ lower than in the upmost simulation. Note that $c_{0}=0.6$. there is no crystallographic relationship of the lamellar grains through the ILBs, which is in further agreement with the experimental findings.

We note that homogeneous nucleation yields globular particles of the primary phase with no impurity particles at their centres, which is in agreement with the observations described in Section 2.1. However, we recall that homogeneous nucleation is not well suited to explain the experimental observations. To see whether heterogeneous nucleation via free growth leads to microstructures that qualitatively agree with 

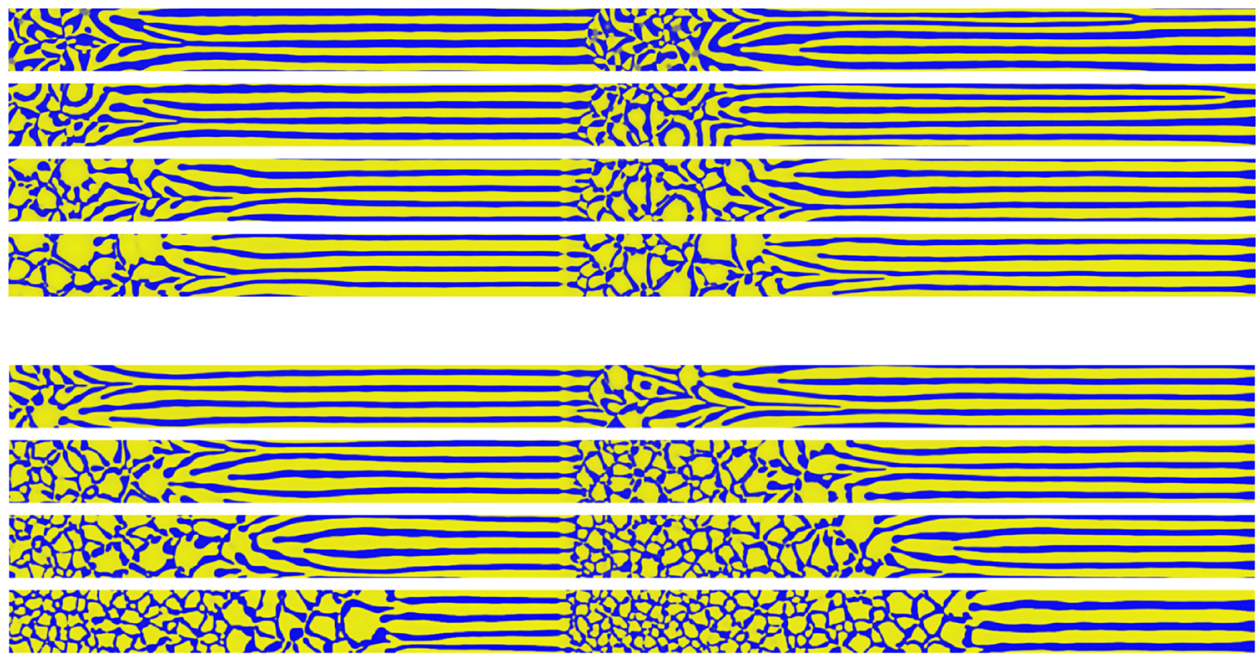

Fig. 11. The effect of alloy concentration on the final microstructure as predicted by the phase-field simulations. From top to bottom, $\mathrm{c}_{0}$ $=0.50,0.55,0.60$ and 0.65 , respectively. experimental observations, we performed a simulation with 400 randomly distributed dormant nucleation sites in the simulation domain (Fig. 9). These sites can be considered as impurity particles, as in the case of the athermal nucleation model by Quested and Greer [26], or partially remelted and spheroidized fragments of the eutectic lamellae from the primary phase produced in the previous heating cycle. The simulated structure at the interlayer boundary is very close to those obtained with homogeneous nucleation (Figs. 7, 8 and 10-12) and in qualitative agreement with the experimental observations.

In our simulations, the thickness of the globular layers depends on the material and process parameters. When the globular layer is formed via homogeneous nucleation, we can adjust its thickness by tuning the parameters that influence nucleation, which are the local temperature, the composition, and the strength of the fluctuations. Of these, only the composition can be changed in an easily controlled, measurable way in the experiments. It is, however, worth to explore how these parameters affect the eutectic microstructure. To save computation time, only a narrow slice of material is simulated in the tests below.

First, we varied the temperature where nucleation happens, by shifting the temperature profile corresponding to the cooling period (see Fig. 6(b)) by $10 \mathrm{~K}$ and $20 \mathrm{~K}$ downwards along the whole sample. Images displaying two full layers obtained under such condition are shown in Fig. 10. As seen on the figures, deeper undercooling means higher nucleation rates, which result in wider globular layers and a higher number of smaller globular particles.

Next, we changed the initial composition of the melt (representing the average composition of the powder mixture in the experiments). We carried out simulations at the eutectic and 3 off-eutectic compositions, $c_{0}=0.50,0.55,0.60$ and 0.65 (Fig. 11). At the eutectic composition, as the phase diagram of our model is also symmetric with respect to the components A and B, a fully symmetric system was obtained: there should be no preference of the nucleation of the B rich phase over the A rich phase. Instead of the simultaneous nucleation of roughly equal numbers of globular particles rich in A or rich in B, which then develop to a eutectic structure, we observed the appearance of globular particles that had a disordered eutectic structure already in their core. This is in contrast with the simulation results at the off-eutectic compositions $\left(c_{0}>0.5\right)$ where the nucleation of B-rich particles is always preferred. This results in a visible difference between the two types of simulations. The one corresponding to the eutectic composition does not, while the ones corresponding to the off-eutectic compositions do have a clearly visible globular structure in the fully solidified state.

Finally, we tuned the amplitude of the Gaussian white noise added to the phase-field equation of motion to represent thermal fluctuations present in the system. We made simulations with 4 different values, 0.5 , $0.67,0.75$, and 1 in relative units (Fig. 12). Although in nature the strength of the fluctuations cannot be easily tuned independently from temperature, these simulations demonstrate the importance of nucleation in forming the microstructure. The larger the noise amplitude, the higher the nucleation rate, which results in wider globular layers of smaller particle size.

\section{Summary and outlook}

Directed Energy Deposition (DED) was used as a method to produce an ultrafine eutectic microstructure composed of BCC-Fe and the hexagonal Laves phase $\mathrm{Fe}_{2} \mathrm{Ti}$ in a binary alloy with a slightly hypereutectic composition of Fe-17.6 at.\% Ti. Lamellar spacings as low as $200 \mathrm{~nm}$ were obtained, however the microstructure is discontinuous across interlayer boundaries. In these regions, i.e. at the bottom of the melt pool, conditions prevail which lead to a globular morphology of the primary $\mathrm{Fe}_{2} \mathrm{Ti}$ phase. 3D microstructure analysis using high resolution synchrotron holographic X-ray computed tomography (HXCT) was successfully performed with a voxel size of $10 \times 10 \times 10 \mathrm{~nm}^{3}$. HXCT was used to characterize the microstructure and to verify if oxide particles or other potential inclusions can be detected in the center of the globular primary $\mathrm{Fe}_{2} \mathrm{Ti}$ particles. This is not the case and hence we conclude that the nucleation of the globular $\mathrm{Fe}_{2} \mathrm{Ti}$ particles is not caused by heterogeneous nucleation. With our phase-field model we also investigated the possibility of nucleation on partially remelted and spherodized lamellae as seed particles. Though the simulations should capture this automatically, with the simple symmetric model system and process parameters used we could not observe this directly. But we have shown that if we assume that these seeds are present in the system, the nucleation and growth of spherical particles of the primary phase is reproduced and the resulting microstructure is very similar to those of obtained by homogeneous nucleation and to the experiments. Then homogeneous nucleation scenarios were further explored in detail by phase field modelling for a generic eutectic phase diagram. Simulation results indeed showed that a layered microstructure similar to the one observed in the experiments can be reproduced using a cyclic temperature history that mimics the melting by the laser beam and the subsequent solidification. Experimental observations suggest yet another mechanism to explain the globular structure of primary phase particles at interlayer boundaries: Most likely these particles grow from partially remelted and spheroidized parts of eutectic lamellae from the previous layers. A dedicated study focusing on the remelting of a solid eutectic structure is required to clarify this issue.

Furthermore, the experimental results were used to estimate the local growth conditions in DED using simple scaling laws: from the measured eutectic spacing $\lambda$ the isotherm velocity $\boldsymbol{v}$ in the melt pool was estimated to reach $\sim 7.5 \times 10^{-3} \mathrm{~m} / \mathrm{s}$ following the Jackson-Hunt 
scaling law $\boldsymbol{v}=\boldsymbol{K}_{J H} / \lambda^{2}$. The local temperature gradient $\boldsymbol{G}$ at the bottom of the melt pool was estimated from the width of the interlayer boundaries $\delta$ and the equilibrium melting /solidification interval of the alloy $\boldsymbol{\Delta} \boldsymbol{T}$. Using $\boldsymbol{G}=\boldsymbol{\Delta T} / \delta$ the temperature gradient was estimated to reach $\sim 2.6 \times 10^{6} \mathrm{~K} / \mathrm{m}$. We wish to highlight that binary eutectic alloys could be used to validate melt pool simulations in the future. The only condition that needs to be checked beforehand is the verification that the coupled zone of the eutectic at case allows achieving coupled growth at high growth velocitites.

\section{Declaration of Competing Interest}

None.

\section{Acknowledgments}

The authors gratefully acknowledge funding through the European M-Era.Net Project "ELAM" funded through national agencies under Federal Ministry for Education and Research (BMBF), Germany, grants number BMBF 03XP0121B, 03XP0121C, the National Research, Development, and Innovation Office (NKFIH), Hungary under contract NN-125832 and Agencia Estatal de Investigación, Spain, under grant number PCIN-2017-11.

The ESRF is acknowledged for the provision of synchrotron facilities at beamline ID16-A in the frame of proposal MA-4351.

\section{References}

[1] S. Akamatsu, M. Plapp, Eutectic and peritectic solidification patterns, Current Opinion in Solid State and Materials Science 20 (1) (2016) 46-54.

[2] K.A. Jackson, J.D. Hunt, Lamellar and Rod Eutectic Growth, Transactions of the Metallurgical Society of AIME Vol. 236 (1966), pp. 1129-1142.

[3] N. Wang, R. Trivedi, Limit of steady-state lamellar eutectic growth, Scr. Mater. 64 (2011) 848-851.

[4] S.C. Gill, W. Kurz, Rapidly solidified Al-cu alloys-II- Calculation of the microstructure selection map, Acta metall mater. 43 (1) (1995) 139-151.

[5] J.M. Park, K.B. Kim, W.T. Kim, M.H. Lee, J. Eckert, D.H. Kim, High strength ultrafine eutectic Fe-Nb-Al composites with enhanced plasticity, Intermetallics 16 (5) (2008) 642-650.

[6] L. Sheng, J.T. Guo, L.Z. Zhou, H.Q. Ye, Microstructure and compressive properties of NiAl-Cr (Mo)-Dy near eutectic alloy prepared by suction casting, Mater. Sci. Technol. 26 (2) (2010) 164-168.
[7] D. Barbier, M.X. Huang, O. Bouaziz, A novel eutectic Fe-15 wt.\% Ti alloy with an ultrafine lamellar structure for high temperature applications, Intermetallics 35 (2013) 41-44.

[8] K. Tokoro, Y. Kimura, Structural and magnetic properties of unidirectionally solidified Fe-Fe2Ti eutectic alloys, Tetsu-to-Hagane, the iron and steel institute of Japan, Volume 60 (1974) 386-396.

[9] Thermo-Calc Software, availableonline, accessed February 2019, www.thermocalc. com,..

[10] C.A. Norlund, R. Trivedi, Eutectic interface configurations during melting, Metall. Mater. Trans. A 31A (2000) 1261-1269.

[11] J.K. Lee, T.H. Courtney, Two-dimensional finite difference analysis of shape instabilities in plates, Metall. Trans. A 20 (8) (1989) 1385-1394.

[12] A. Samanta, M.E. Tuckerman, T.Q. Yu, E. Weinan, Microscopic mechanisms of equilibrium melting of a solid, Science 346 (6210) (2014) 729-732.

[13] L.K. Wu, B. Xu, Q.L. Li, W. Liu, Self-instability of finite sized solid-liquid interfaces, Sci. Rep. 5 (2015) 18466.

[14] J.C. da Silva, A. Pacureanu, Y. Yang, S. Bohic, C. Morawe, R. Barrett, P. Cloetens, Efficient concentration of high-energy x-rays for diffraction-limited imaging resolution, Optica 4 (5) (2017) 492-495.

[15] G. Requena, P. Cloetens, W. Altendorfer, C. Poletti, D. Tolnai, F. Warchomicka, H.P. Degischer, Sub-micrometer synchrotron tomography of multiphase metals using Kirkpatrick-Baez optics, Scr. Mater. 61 (2009) 760-763.

[16] J. Schindelin, I. Arganda-Carreras, E. Frise, Fiji: An open-source platform for biological-image analysis, Nat. Methods 9 (2012) 676-682.

[17] G.C. Requena, P. Degischer, E.D. Marks, E. Boller, Microtomographic study of the evolution of microstructure during creep of an AlSiCuMgNi alloy reinforced with Al2O3 short fibres, Mater. Sci. Eng. A 487 (2008) 99-107.

[18] T. Hildebrand, P. Rüegsegger, A new method for the model-independent assessment of thickness in three-dimensional images, J. Microsc. 185 (1) (1997) 67-75.

[19] D. Lewis, T. Pusztai, L. Gránásy, J. Warren, W. Boettinger, Phase field models for eutectic solidification, JOM - J. Min. Met. Mat. S. 56 (4) (2004) 34-39.

[20] L. Gránásy, T. Börzsönyi, T. Pusztai, Nucleation and bulk crystallization in binary phase field theory, Phys. Rev. Lett. 88 (2002) 1-4 206105.

[21] L. Gránásy, T. Pusztai, T. Börzsönyi, J.A. Warren, J.F. Douglas, A general mechanism of polycrystalline growth, Nat. Mater. 3 (2004) 645-650.

[22] L. Gránásy, T. Pusztai, G. Tegze, J.A. Warren, J.F. Douglas, Growth and form of spherulites, Phys. Rev. E 72 (2005) 011605-1-15.

[23] L. Gránásy, L. Rátkai, A. Szállás, B. Korbuly, G.I. Tóth, L. Környei, T. Pusztai, Phasefield modeling of polycrystalline solidification: from needle crystals to spherulites a review, Metall. Mater. Trans. A 45 (4) (2014) 1694-1719.

[24] C. Fetzer, L. Gránásy, T. Kemény, E. Kótai, M. Tegze, I. Vincze, W. Howing, F. van der Woude, Laser-melted amorphous and crystalline Fe-B alloys, Phys. Rev. B 42 (1990) 548-554.

[25] L. Gránásy, G.I. Tóth, J.A. Warren, F. Podmaniczky, G. Tegze, L. Rátkai, T. Pusztai, Phase-field modeling of crystal nucleation in undercooled liquids - a review, Prog. Mater. Sci. 106 (2019) 1-51 art. no. 100569.

[26] T.E. Quested, A.L. Greer, Athermal heterogeneous nucleation of solidification, Acta Mater. 53 (2005) 2683-2692.

[27] L. Wei, Y. Cao, X. Lin, W. Huang, Cellular automaton simulation of the growth of anomalous eutectic during laser remelting process, Materials 11 (2018) 1844/1-9. 